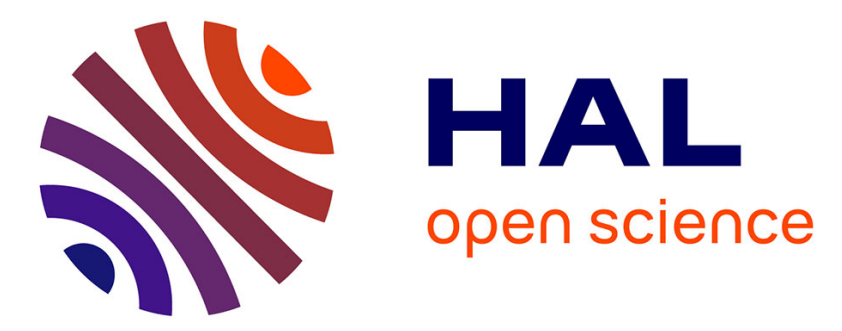

\title{
Centralized and decentralized bitcoin markets: Euro vs USD vs GBP
}

\author{
Roman Matkovskyy
}

\section{To cite this version:}

Roman Matkovskyy. Centralized and decentralized bitcoin markets: Euro vs USD vs GBP. Quarterly Review of Economics and Finance, 2019, 71, pp.270-279. 10.1016/j.qref.2018.09.005 . hal-02127175

\section{HAL Id: hal-02127175 \\ https://hal-rennes-sb.archives-ouvertes.fr/hal-02127175}

Submitted on 21 Oct 2021

HAL is a multi-disciplinary open access archive for the deposit and dissemination of scientific research documents, whether they are published or not. The documents may come from teaching and research institutions in France or abroad, or from public or private research centers.
L'archive ouverte pluridisciplinaire HAL, est destinée au dépôt et à la diffusion de documents scientifiques de niveau recherche, publiés ou non, émanant des établissements d'enseignement et de recherche français ou étrangers, des laboratoires publics ou privés.

\section{다)(1) $(5$}

Distributed under a Creative Commons Attribution - NonCommercial| 4.0 International 


\title{
Centralized and Decentralized Bitcoin Markets: Euro vs USD vs GBP
}

\author{
Roman Matkovskyy \\ Rennes School of Business, Department of Finance and Accounting, 2 rue Robert d'Arbrissel \\ CS 76522, Rennes, 35065 France
}

Tel.: +33 (0)2 99546365

E-mail: roman.matkovskyy@rennes-sb.com

\begin{abstract}
In this study, I compared the euro, U.S. dollar, and British pound sterling (GBP) centralized and decentralized bitcoin cryptocurrency markets in terms of return volatility and interdependency. This comparison showed the decentralized bitcoin market has higher volatility and the centralized markets have higher tail dependence regarding returns. The volatility analysis results are contrary to the established leverage reasons that market drops cause volatility. The results demonstrate a higher left tail dependence is in line with the general pattern in "traditional" financial markets which more extreme dependent in downturns. It was also shown trade volume increases as prices decrease, demonstrating participants' lack of confidence and consensus in a price-jump period.
\end{abstract}

JEL classification: G1, C14, C22

Keywords: Bitcoin; centralized exchange; decentralized exchange; volatility; dependency; ARMA-GARCH copula 


\title{
Centralized and Decentralized Bitcoin Markets: Euro vs USD vs GBP
}

\author{
Abstract \\ In this study, I compared the euro, U.S. dollar, and British pound sterling (GBP) centralized \\ and decentralized bitcoin cryptocurrency markets in terms of return volatility and \\ interdependency. This comparison showed the decentralized bitcoin market has higher \\ volatility and the centralized markets have higher tail dependence regarding returns. The \\ volatility analysis results are contrary to the established leverage reasons that market drops \\ cause volatility. The results demonstrate a higher left tail dependence is in line with the \\ general pattern in "traditional" financial markets which more extreme dependent in \\ downturns. It was also shown trade volume increases as prices decrease, demonstrating \\ participants' lack of confidence and consensus in a price-jump period.
}

JEL classification: G1, C14, C22.

Keywords: Bitcoin; centralized exchange; decentralized exchange; volatility; dependency; ARMA-GARCH copula.

\section{Acknowledge}

The author wishes to acknowledge the editor and two anonymous reviewers for their detailed and helpful comments on the manuscript. 


\section{Introduction}

Bitcoin, a communication protocol used in virtual currency transactions (Böhme et al., 2015), has recently entered into and assumed a place in financial markets and portfolio management (Dyhrber, 2016). In December 2017, bitcoin was approved by the U.S. Commodities and Futures Trading Commission (CFTC), which made the Chicago Board Options Exchange (CBOE) and CME bitcoin futures contract launches possible. This approval opened up bitcoin trading to a larger group of investors and traders and thus allowed more international participants to become involved in this market. ${ }^{1}$ Despite bitcoin being a homogeneous and identical virtual good across all online markets in which it is traded, its prices behave differently across these markets due to their characteristics' variations (Pieters \& Vivanco, 2017), and high fluctuations in bitcoin prices have resulted in periods of high volatility.

There are two main bitcoin markets: centralized and decentralized markets (exchanges). Centralized bitcoin exchanges include intermediaries such as companies that act as a proxy in order to facilitate trading. Unlike centralized exchanges, the decentralized market is a personto-person (P2P) bitcoin trading site that allows users to post advertisements indicating exchange rates and payment methods for buying or selling bitcoins without disclosing their identities. Trading in the decentralized bitcoin markets has disadvantages, however, because the centralized exchanges offer significantly better trading functionalities. But the major centralized exchanges are not immune to difficulties and have experienced delays and technical difficulties in transactions. For instance, Kraken and other centralized exchanges have halted deposits and withdrawals without warning at various times.

Recently, various aspects of cryptocurrencies, particularly of bitcoins, have drawn increasing research attention. For instance, Luther and Salte's (2017) focus on bitcoin-related apps found downloads of these apps depended on crises occurring in banking systems. Bouri

\footnotetext{
${ }^{1}$ As of December 2017, the bitcoin peaked with an estimated transaction volume of USD \$4,652,736,998 and market capitalization of USD \$325,000,000,000 (Blockchain.info, 2018).
} 
et al. (2017a) and Bouri et al. (2017b) studied the issues of hedging and safe-haven properties of cryptocurrencies. Urquhart (2017) documented that price and volume have a significant positive relationship with price clustering in bitcoin, and Balcilar et al. (2017) showed that volume cannot be used to predict the volatility of bitcoin returns at any point of the conditional distribution. Katsiampa (2017), based on goodness-of-fit tests, showed that the AR-CGARCH model can better explain bitcoin price volatility. Nadarajah and Chu (2017) and Urquhart (2016) demonstrated the high inefficiency of bitcoin, and Charfeddine and Maouchi (2018) also confirmed the inefficiency of the bitcoin market. Phillip et al. (2018) showed in their study of 224 cryptocurrencies that they have some common features (i.e., leverage effects and Student-t error distributions). Blau (2018) demonstrated that speculative trading is not associated with higher levels of volatility in bitcoin, and in analyzing bitcoin volatility, Conrad et al. (2018) found it is closely linked to global economic activity.

These papers, however, mainly focused on centralized U.S. dollar bitcoin markets. The empirical comparison of return volatility and the correlation of the centralized and decentralized bitcoin markets using different currencies has been largely ignored. Such research could be potentially useful in reducing risks in investment decision making. Thus, in this study, I fill this gap by comparatively analyzing volatility and correlation among the main euro, U.S. dollar, and British pound bitcoin exchanges ${ }^{2}$ as well as between the centralized (e.g., Kraken, GDAX-CoinsBank, ${ }^{3}$ bitcoin.de, Bitstamp, Rock Trading, and the exchangebacked peer-to-peer marketplace Coinfloor) and decentralized (P2P) exchanges (e.g., LocalBitcoins) to contribute to a better understanding of the cryptocurrency market's behavior.

For this purpose, I analyzed dependences across the selected markets by applying tail copulas and modeling the dynamics of the average values and variances of the time series

\footnotetext{
${ }^{2}$ China is excluded from the analysis because Beijing shut down all virtual exchanges.

${ }^{3}$ GDAX is CoinsBank now.
} 
using multivariate models. These included the generalized autoregressive conditional heteroskedasticity $(\mathrm{GARCH})$ model (on the residuals from the autoregressive-movingaverage [ARMA] models), a multivariate exponentially weighted moving average (EWMA) for the covariance matrix, and a multivariate model based on copulas that uses the residuals of the ARMA-GARCH process.

The findings provide the first empirical evidence on the dynamics of return volatility and interdependence of the euro, U.S. dollar, and British pound centralized and decentralized bitcoin markets. These were analyzed jointly and, thus, contribute to a better understanding of behavior of the bitcoin centralized and decentralized markets that use different currencies. The results can help shed light on timely issues researchers, practitioners, and policymakers face in terms of risk reduction in bitcoin investment decision making.

The results extend the findings of Blau (2018), Katsiampa (2017), and Klein et al. (2018) by showing decentralized markets have higher volatility and centralized markets have higher tail dependence in terms of returns. The volatility analysis results are contrary to the accepted leverage reason that market drops cause volatility. The results demonstrate the decentralized bitcoin markets are more interdependent, but a price setting in the P2P bitcoin markets is not correlated over time or across markets. Correlation between markets is not stable over time and is higher for the centralized U.S. dollar and British pound exchanges. The estimates show the centralized bitcoin markets demonstrate a higher left tail dependence that is in line with the general pattern of the "traditional" financial markets, which are more extreme dependent in downturns.

Analysis also revealed trade volume increases as prices decrease, demonstrating participants' lack of confidence and consensus in the price-jump period. The existing pattern can also mean that based on their sentiments, investors may overreact because they do not know how the precise technique to estimate the bitcoin price. 
Based on this thinking, the obtained results are potentially useful to researchers, practitioners, and participants in the highly volatile bitcoin market to make better investment and risk management decisions.

The structure of this study is as follows. The models used are presented in Section 2, the model results are discussed in Section 3, and the study conclusions are offered in Section 4. The appendix furnishes supplementary material.

\section{Methodology}

The GARCH framework is frequently used as an efficient instrument to measure the interdependence of returns and volatilities across stock markets, and in a growing stratum of literature, these empirical models and measurements are also applied to bitcoin volatility analyses. Katsiampa (2017) proved the AR-CGARCH model can better explain bitcoin price volatility, and Chan et al. (2018) used pairwise GARCH models and constant conditional correlation models to test the dynamic hedging abilities of bitcoin. Klein et al. (2018) applied a BEKK-GARCH model to estimate time-varying conditional correlations between bitcoin and gold. Symitsi and Chalvatzis (2018) used an asymmetric multivariate VAR-GARCH model to study spillover effects between bitcoin and energy and technology companies. Moreover, Baur et al. (2018) used GARCH models to demonstrate that bitcoin shows distinctively different return volatility and correlation characteristics compared to other financial assets.

Some recent studies on bitcoin have focused on distributions, which allow for asymmetry as well as fat tails. For example, Bouri et al. (2018) applied a copula-based approach to document a right tail dependence between the global financial stress index and bitcoin returns. They also showed limited directional predictability from the global financial stress index regarding bitcoin returns in the medium term. 
In this study, I used well-established models (i.e., tail copulas, GARCH models [on the residuals from the ARMA models], a multivariate EWMA for the covariance matrix, and a multivariate model based on copulas that uses the residuals of the ARMA-GARCH process). I start with a kernel density estimation to depict the distributions. The determination of the optimal bandwidth was based on choosing the one that minimizes an optimality criterion (e.g., the mean integrated squared error).

The multivariate EWMA models for the covariance matrix were then built to show the volatility of returns across different markets. Among the attractive properties EWMA has over GARCH modelling is in the greater weight put upon more recent observations. The EWMA model was proposed in Riskmetrics (1996), where the variances and covariances are as in the IGARCH-type models. In general, this model is $\hat{\Sigma}_{t}=\lambda \widehat{\Sigma}_{t-1}+(1-\lambda) \hat{a}_{t-1} \hat{a}_{t-1}^{\prime}$, where $\hat{a}_{t}$ are residual from the mean equation, and $\lambda(0<\lambda<1)$ is the persistence parameter, which equals 0.96 for daily observations (Riskmetrics, 1996).

Correlation was tested by different measurements, namely tail dependence, tail copulas, and Spearman's rho. The well-established tail dependence coefficients (TDC) based on the concept of copulae were used as the scalar measures for correlation in tails (see, for instance, Frahm et al., 2005; Schmidt and Stadtmüller, 2006). They showed how extreme values in one series are likely to be accompanied by equally large or low extreme values in other series. A tail copula is defined as a function that explains the dependence structure of joint distributions in lower (left) or upper (right) tails. Let $F$ be a distribution function with corresponding copula $C$. Then, the function $\Lambda_{L}: \overline{\mathbb{R}}_{+}^{2} \rightarrow \mathbb{R}$ is called a lower (left) tail copula associated with $F$, if the following limit exists everywhere on $\overline{\mathbb{R}}_{+}^{2}$ :

$$
\Lambda_{L}(x, y):=y \lim _{t \rightarrow \infty} \mathrm{tC}(\mathrm{x} / t, \mathrm{y} / t)
$$

Analogously, the function $\Lambda_{U}: \overline{\mathbb{R}}_{+}^{2} \rightarrow \mathbb{R}$ is defined as an upper tail copula if the 
following limit exists on $\overline{\mathbb{R}}_{+}^{2}$ :

$$
\Lambda_{U}(x, y):=y \lim _{t \rightarrow \infty} t \bar{C}(x / t, y / t)
$$

According to Schmidt and Stadtmüller (2006),

$$
\Lambda_{L}(x, y)=y \lim _{t \rightarrow \infty} P(U \leq x / t|V \leq y| t)=\lim _{t \rightarrow \infty} t P\left(X \leq G^{-1}(x / t), Y \leq H^{-1}(y / t)\right)
$$

$$
\Lambda_{U}(x, y)=\lim _{t \rightarrow \infty} t P\left(X>G^{-1}(1-x / t), Y>H^{-1}(1-y / t)\right)
$$

where $\Lambda_{L}: \overline{\mathbb{R}}_{+}^{2} \rightarrow \mathbb{R}$ is a lower tail copula, the function $\Lambda_{U}: \overline{\mathbb{R}}_{+}^{2} \rightarrow \mathbb{R}$ is an upper tail function, and $C$ is a copula associated with a distribution function; $\overline{\mathbb{R}}_{+}^{2}:=[0, \infty]^{2}\{(\infty, \infty)\}$. It means that a lower (left) tail copula and an upper (right) tail copula describe the dependence structure of the extreme-value distribution, $C$.

The tail dependence coefficients were estimated in a non-parametrical way as in Schmidt and Stadtmüller (2006) (see Appendix 1). This approach establishes the asymptotic normality and strong consistency, and received estimates provide the general pattern of interdependence. Its application derives a smaller finite sample bias than other approaches such as those of Einmahl et al. (2001) and Fermanian et al. (2004), to name a few. Tail dependence was calculated by applying ARMA-GARCH-copula models (i.e., by fitting and testing the Gaussian, t, and Gumbel copulas to residuals from the ARMA-GARCH models in the way as discussed in Cherubini et al. [2004]). The copula approach has several advantages (see Cherubini, Luciano and Vecchiato, 2004; Frees and Valdez, 1998; Nelson, 2006). For example, different marginal distributions can be fitted and different types of dependence structures can be analyzed without imposing restrictions that increases a model flexibility.

The Gaussian copula (Lee, 1983) is as follows: 


$$
\begin{array}{r}
C\left(u_{1}, u_{2} ; \theta\right)=\Phi_{G}\left(\Phi^{-1}\left(u_{1}\right), \Phi^{-1}\left(u_{2}\right) ; \theta\right)= \\
\int_{-\infty}^{\Phi^{-1}\left(u_{1}\right)} \int_{-\infty}^{\Phi^{-1}\left(u_{2}\right)} \frac{1}{2 \pi\left(1-\theta^{2}\right)^{1 / 2}} \times\left\{\frac{-\left(s^{2}-2 \theta s t+t^{2}\right.}{2\left(1-\theta^{2}\right)}\right\} d s d t
\end{array}
$$

where $\Phi$ is the CDF of the standard normal distribution, $\Phi_{G}\left(u_{1}, u_{2}\right)$ is the standard normal distribution, and $\theta$ is the correlation parameter in the interval $(-1,1)$.

Student t copula is defined as (Genz, 2009):

$$
C^{t}\left(u_{1}, u_{2} ; \theta_{1}, \theta_{2}\right)=\int_{-\infty}^{t_{\theta_{1}}^{-1}\left(u_{1}\right)} \int_{-\infty}^{t_{\theta 2}^{-1}\left(u_{2}\right)} \frac{1}{2 \pi\left(1-\theta_{2}^{2}\right)^{1 / 2}} \times\left\{1+\frac{\left(s^{2}-2 \theta_{2} s t+t^{2}\right)}{v\left(1-\theta_{2}^{2}\right)}\right\}^{-\left(\theta_{1}+2\right) / 2} d s d t(6)
$$

where $t_{\theta_{1}}^{-1}\left(u_{1}\right)$ is the inverse of the CDF of the standard univariate t-distribution with $\theta_{1}$ degrees of freedom. $\theta_{1}$ controls the heaviness of the tails (i.e., increasing the value of $\theta_{1}$ and decreasing the tendency to exhibit extreme co-movements: if $\theta_{1}<3$, then the variance does not exist, and if $\theta_{1}<5$, the fourth moment does not exist).

The Gumbel (1960) copula is also an Archimedean copula and is given by

$$
C\left(u_{1}, u_{2} ; \theta\right)=\exp \left(-\left(\tilde{u}_{1}^{\theta}+\tilde{u}_{2}^{\theta}\right)^{1 / \theta}\right)
$$

where $\tilde{u}_{j}=-\log \tilde{u}_{j}$.

Maximum likelihood was used to derive the estimates. Finally, I tested whether the correlation is stable over time by means of Spearman's rho.

\section{Data and empirical results}

Due to data availability for centralized and decentralized bitcoin markets that use the euro, U.S. dollar, and British pound, I formed the following datasets. For the centralized bitcoin exchanges, I used data provided by GDAX/CoinsBank (for the euro, U.S. dollar, and British pound), Kraken (for the euro and U.S. dollar), Rock Trading (for the euro and U.S. dollar), Bitcoin.de (for the euro), Bitstamp (for the U.S. dollar), and the first exchange-backed peer- 
to-peer marketplace, Coinfloor (for the British pound). LocalBitcoins was used to form a dataset on a decentralized exchange (a P2P market). To calculate returns, I used the daily closing prices for bitcoin in euros, U.S. dollars, and British pounds from April 27, 2015 to August 9, 2018. ${ }^{4}$

The estimated kernel densities of the returns for the euro, U.S. dollar, and British pound bitcoin markets are presented in Figure 1, which depicts long tails of the return distributions as well as the higher skewness of the distribution of the bitcoin returns in the U.S. dollar centralized markets.

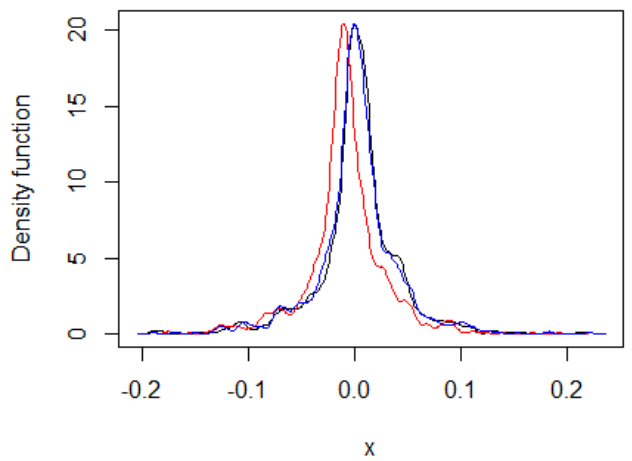

a) centralized exchanges

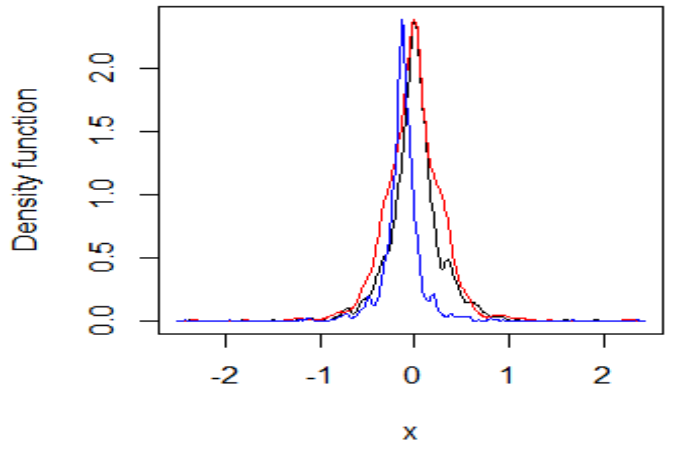

b) decentralized exchange

Fig. 1. Kernel density of bitcoin returns in the euro (black), U.S. dollar, and British pound exchange markets over 2015-2018.

The estimated multivariate EWMA model for the covariance matrix derives the following pattern of return volatility (see Figures 2 and 3):

GDAX
Kraken
Bitcoin.de
The Rock Traidind

\footnotetext{
${ }^{4}$ Due to data availability, for the dataset Rock Trading-Coinfloor, the dataset covers the period of April 27, 2015 to January 3, 2018.
} 


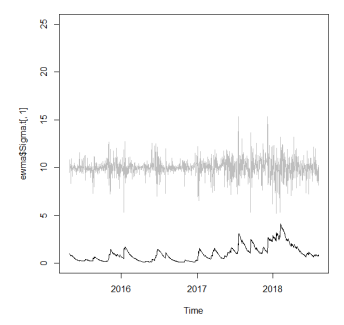

*Residuals from ARMA(2,

2)-GARCH(1, 1)

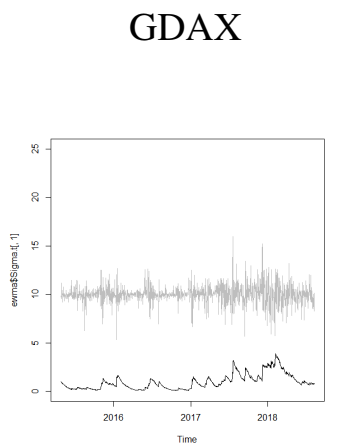

*Residuals from $\operatorname{ARMA}(0,1)$ $\operatorname{GARCH}(1,1)$

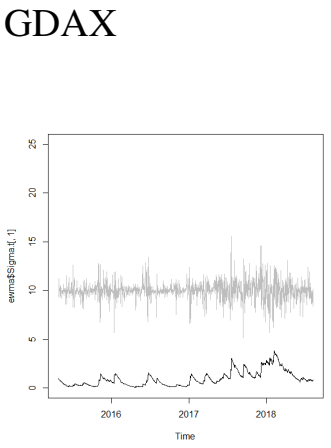

*Residuals from ARMA $(0$,

1)-GARCH(1, 1)

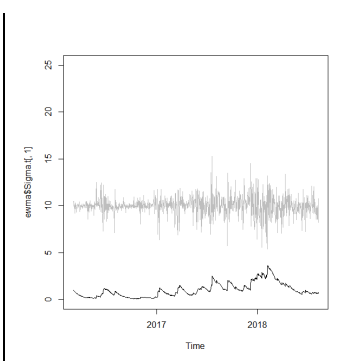

*Residuals from $\operatorname{ARMA}(0,1)$ $\operatorname{GARCH}(1,1)$

Panel a. Return volatility in the euro market
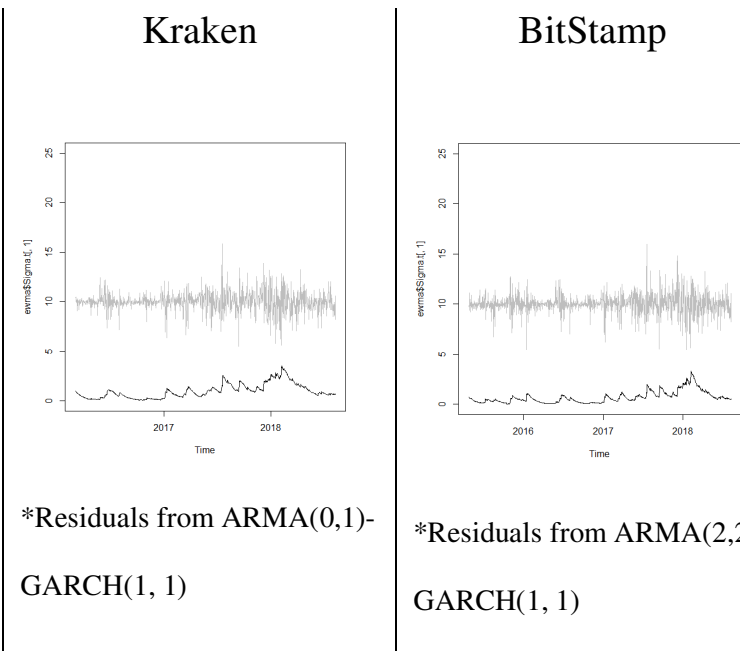

*Residuals from ARMA(2,2)-

$\operatorname{GARCH}(1,1)$

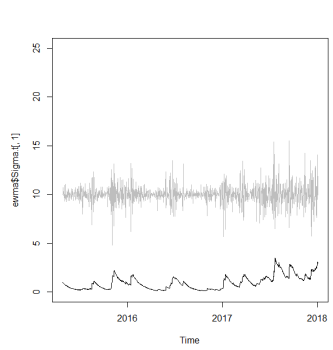

*Residuals from $\operatorname{ARMA}(2,0)$ $\operatorname{GARCH}(1,1)$

Panel b. Return volatility in the U.S. dollar market

The rock traidind

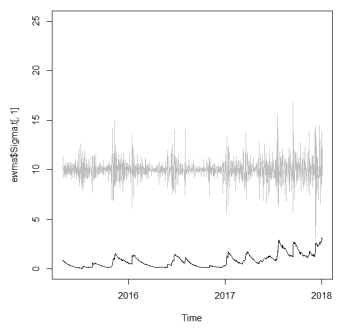

*Residuals from ARMA(1,0)$\operatorname{GARCH}(1,1)$

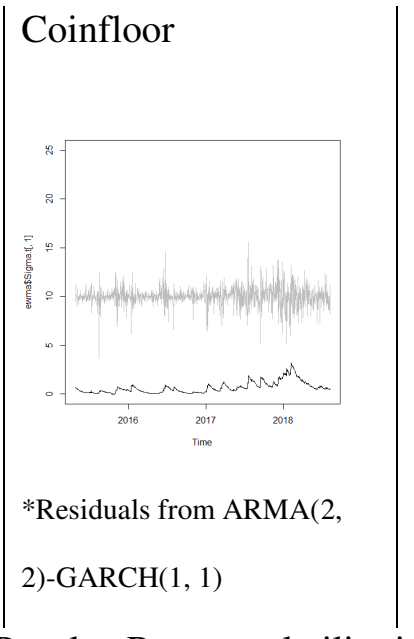

Panel c. Return volatility in the British pound market

Fig. 2. Volatility of the centralized bitcoin markets (the EWMA model). 
Note: * residuals are derived from the respective ARMA-GARCH models, selected based on the AIC/BIC values.

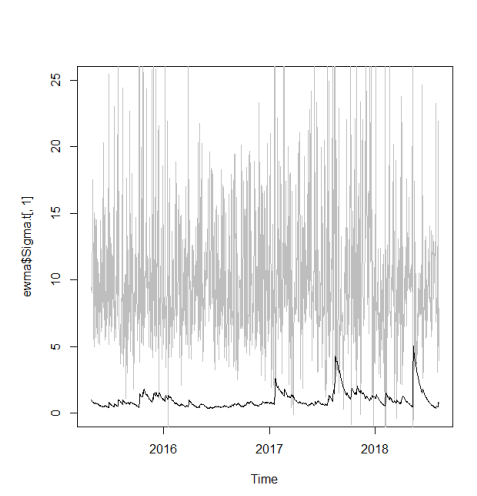

*Residuals from ARMA $(0,1)$ -

$\operatorname{GARCH}(1,1)$

Panel a. Volatility of returns in the euro market
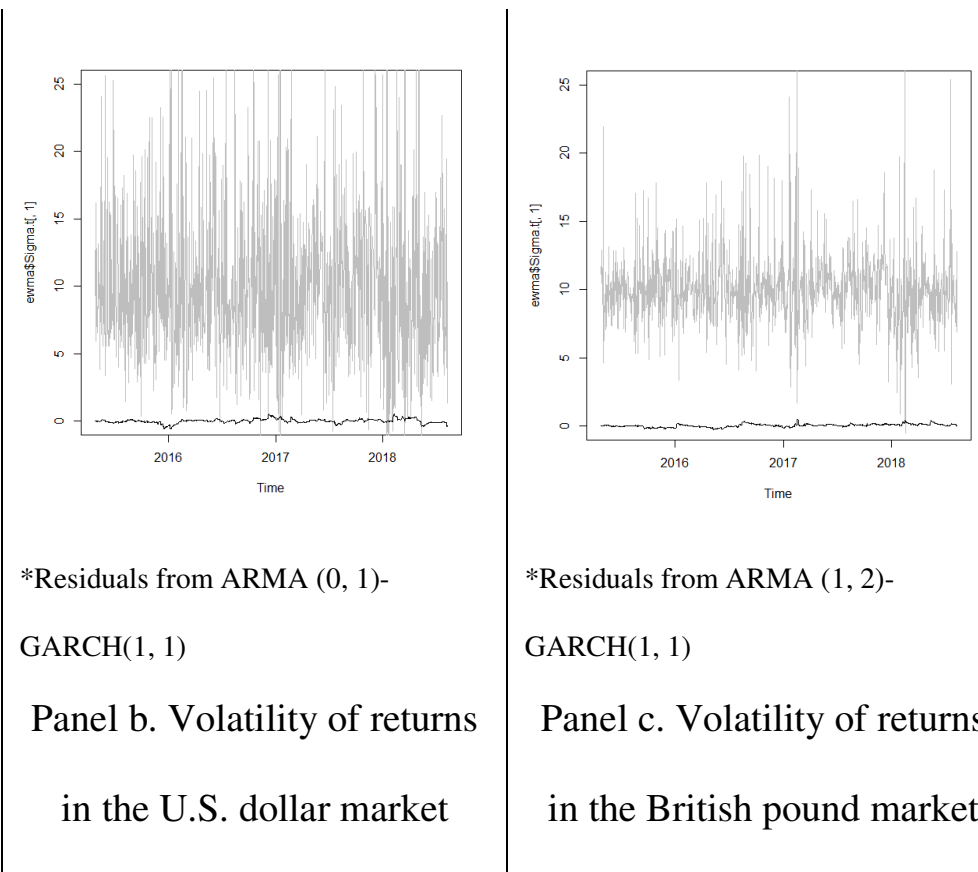

Panel c. Volatility of returns in the British pound market

Fig. 3. Volatility of the decentralized bitcoin markets, LocalBitcoins (the EWMA model).

Note: * residuals are derived from the respective ARMA-GARCH models, selected based on the AIC/BIC values.

Figures 2 and 3 show that volatility in the decentralized exchanges is significantly higher than in the centralized ones. One can observe that in the centralized markets, volatility increases as prices jump (including the exchange-backed peer-to-peer marketplace Coinfloor). It is contrary to simple leverage reasons that market drops cause volatility. Compared to "traditional" institutional money, the significant increases in a price are not typically accompanied by jumps in volatility.

The results also show, that in the centralized bitcoin markets volatility increased after the announcement of trading in Bitcoin futures. This is in line with Corbet's et al. (2018) findings. 
Regarding trade volume, it increased as prices decreased (see Figure A1 in the appendix), demonstrating a lack of confidence and consensus of a large number of participants in the price-jump period. Thus, volumes did not go with the trend.

Regarding correlation in tails, the tail dependence coefficients showed the following pattern (see Tables 1 and 2):

Table 1. Lower (left) and upper (right) tails of the Bitcoin return dependency, centralized exchanges.

\begin{tabular}{|c|c|c|c|c|c|c|c|c|c|}
\hline \multirow{2}{*}{$\begin{array}{l}\text { Bitcoin } \\
\text { currency } \\
\text { market }\end{array}$} & \multicolumn{3}{|c|}{ GDAX } & \multicolumn{3}{|c|}{$\begin{array}{l}\text { Kraken (euro, U.S. } \\
\text { dollar)/GDAX (British } \\
\text { pound) }\end{array}$} & \multicolumn{3}{|c|}{ Bitcoin.de/ BitStamp/Coinfloor } \\
\hline & Euro & $\begin{array}{l}\text { U.S. } \\
\text { dollar }\end{array}$ & $\begin{array}{l}\text { British } \\
\text { pound }\end{array}$ & Euro & $\begin{array}{l}\text { U.S. } \\
\text { dollar }\end{array}$ & $\begin{array}{l}\text { British } \\
\text { pound }\end{array}$ & $\begin{array}{c}\text { Euro, } \\
\text { Bitcoin.de }\end{array}$ & $\begin{array}{c}\text { U.S. } \\
\text { dollar, } \\
\text { BitStamp }\end{array}$ & $\begin{array}{c}\text { British } \\
\text { pound, } \\
\text { Coinfloor }\end{array}$ \\
\hline \multicolumn{10}{|c|}{ Lower tail of the Bitcoin returns dependency } \\
\hline Euro & 1 & 0.882 & 0.88 & 1 & 0.828 & 0.759 & 1 & 0.62 & 0.59 \\
\hline $\begin{array}{l}\text { U.S. } \\
\text { dollar }\end{array}$ & & 1 & 0.91 & & 1 & 0.862 & & 1 & 0.82 \\
\hline $\begin{array}{l}\text { British } \\
\text { pound }\end{array}$ & & & 1 & & & 1 & & & 1 \\
\hline \multicolumn{10}{|c|}{ Upper tail of the Bitcoins returns dependency } \\
\hline Euro & 1 & 0.85 & 0.824 & 1 & 0.862 & 0.896 & 1 & 0.62 & 0.56 \\
\hline $\begin{array}{l}\text { U.S. } \\
\text { dollar }\end{array}$ & & 1 & 0.85 & & 1 & 0.897 & & 1 & 0.82 \\
\hline $\begin{array}{l}\text { British } \\
\text { pound }\end{array}$ & & & 1 & & & 1 & & & 1 \\
\hline
\end{tabular}


Based on Table 1, one can assume there is a significant tail correlation in bitcoin returns across the centralized markets, especially in the lower (left) tail. The results obtained for Rock Trading also demonstrated the analogous pattern. Similar results were derived from the ARMA-GARCH copula models (see Figure A2 in the Appendix). Also, tail correlation within the same exchanges was higher than between currency pairs across different exchanges.

Several tail copulas studies, such as Ang and Chen (2002), Giacomini et al. (2009), Hu (2006), and Hong et al. (2007), demonstrated that "traditional" financial markets are more extreme dependent in downturns; thus, a lower tail coefficient is superior to an upper tail one. Therefore, the results support this hypothesis also for the centralized cryptocurrency markets.

The tail dependence coefficients for the P2P bitcoin market were different from those obtained for the centralized markets; there was no significant tail dependence in bitcoin returns (see Table 2 here and Figure A3 in the Appendix).

Table 2. Lower (left) and upper (right) tails of the bitcoin return dependency, the decentralized exchange

\begin{tabular}{|c|c|c|c|}
\hline \multirow{2}{*}{$\begin{array}{c}\text { Bitcoin currency } \\
\text { market }\end{array}$} & \multicolumn{3}{|c|}{ Decentralized exchange, LocalBitcoins } \\
\cline { 2 - 4 } & Euro & U.S. dollar & British pound \\
\hline \multicolumn{2}{|c|}{ Lower tail of the Bitcoin returns dependency } \\
\hline Euro & 0.03 & 0 \\
\hline U.S. dollar & & 1 & 0.029 \\
\hline British pound & & & 1 \\
\hline \multicolumn{2}{|c|}{ Upper tail of the Bitcoins returns dependency } \\
\hline Euro & 1 & 0.0 & 0.03 \\
\hline U.S. dollar & & 1 & 0.029 \\
\hline British pound & & & 1 \\
\hline
\end{tabular}


Because correlation is not linear and variance is not constant, Spearman's rho was applied to test stability of correlation over time between the pairs of the selected markets (see Figure 4). Figures 4 and 5 show, in general, the correlation was not stable over time and was higher for the centralized exchanges. The currency pairs of the analyzed decentralized bitcoin market were less correlated, and this correlation was more volatile. In general, the estimates showed the correlation between the euro and U.S. dollar centralized markets was slightly higher, and the correlation between the currency pairs was higher within the same exchange. The only exception was the U.S. dollar-British pound, where the correlation between Kraken (U.S. dollar)-GDAX (British pound) and Bitstamp (U.S. dollar)-Coinfloor (British pound) was significantly high.

GDAX (euro, U.S. dollar, British pound)
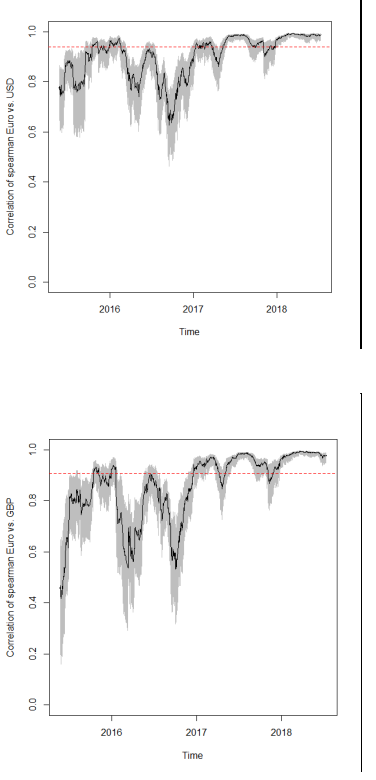

Kraken (euro, U.S. dollar), GDAX (British pound)

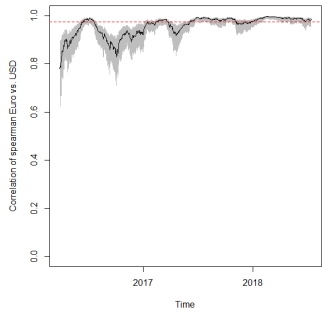

Panel a. Euro vs. U.S. dollar

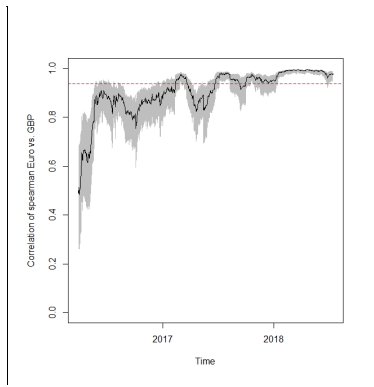

Panel b. Euro vs. British pound
Bitcoin.de (euro), BitStamp (U.S. dollar), Coinfloor (British pound) (euro, U.S. dollar) Coinfloor (British pound)
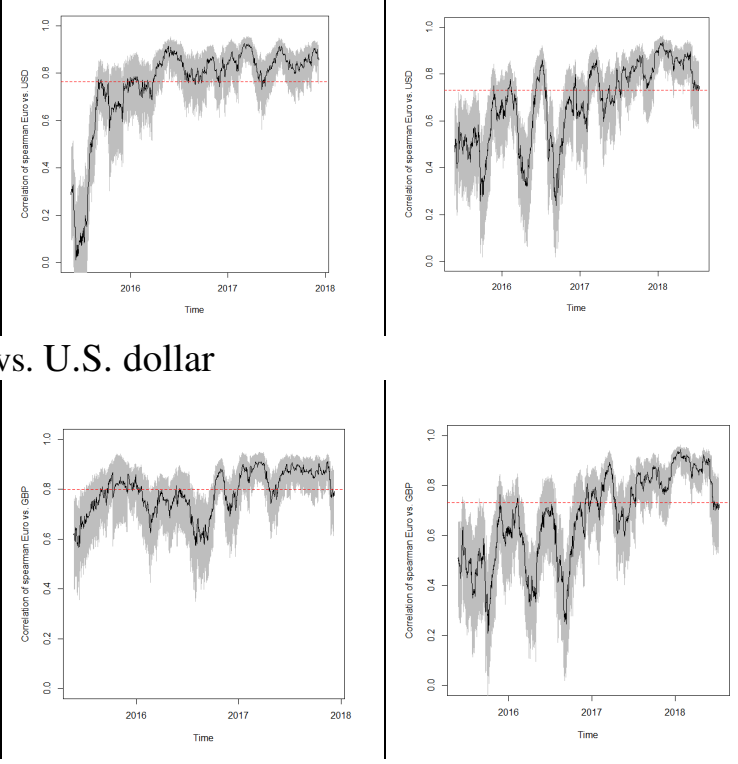

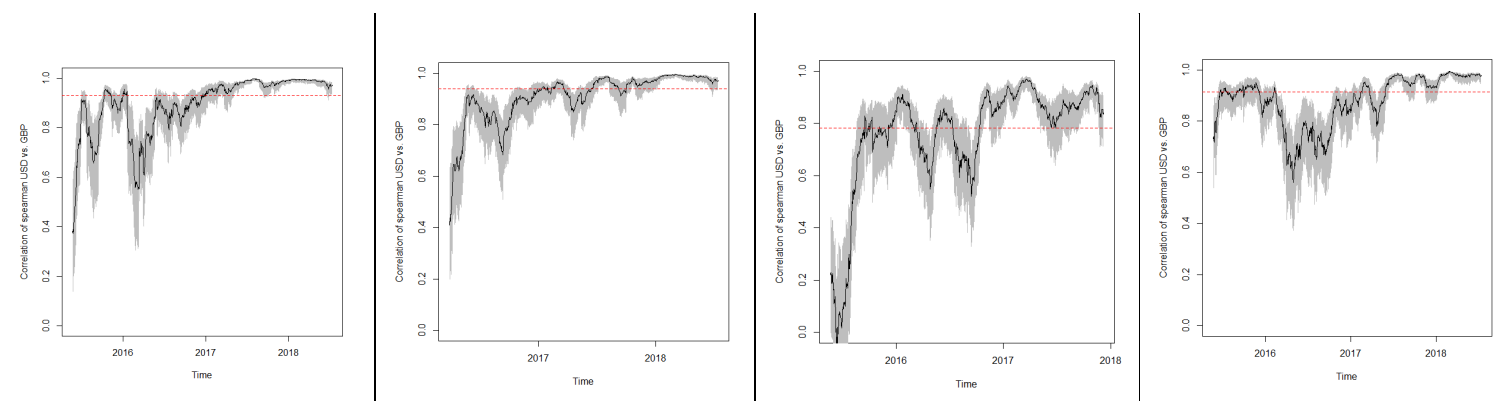

Panel c. U.S. dollar vs. British pound

Fig. 4. Correlation over time between the currencies across the centralized bitcoin exchanges,

Spearman's rho.
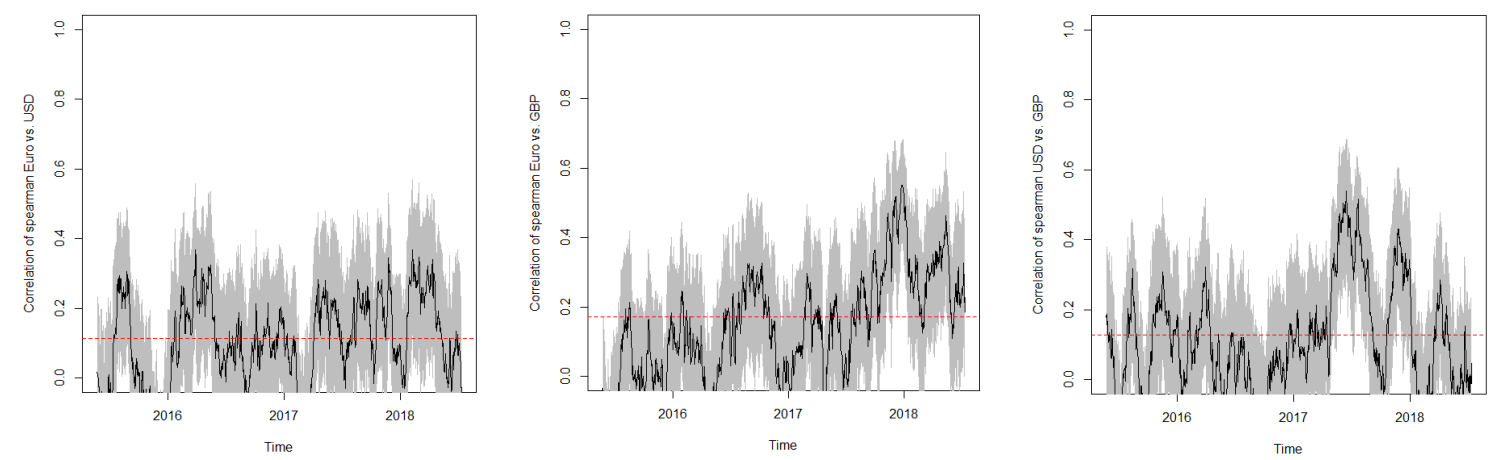

Panel a. Euro vs U.S. dollar

\section{Panel b. Euro vs British}

Panel c. U.S. dollar vs British pound pound

Fig. 5. Correlation over time between the currencies, decentralized bitcoin exchange, Spearman's rho.

\section{Conclusion}

The performed analysis depicts the correlation between the currency pairs across the decentralized (LocalBitcoins) and six centralized bitcoin markets (GDAX, Kraken, Bitcoin.de, Bitstamp, Rock Trading, and the exchange-backed peer-to-peer marketplace, Coinfloor). The estimates derived reasonable results and were consistent with the data provided. 
The results showed that the decentralized bitcoin exchange has higher volatility than the centralized markets. In the centralized markets, volatility increased as prices jumped, but that was not the case in the decentralized exchanges. The volatility analysis results are contrary to the conventional leverage reason that market drops cause volatility. Thus, bitcoin price increases cause an increase in risk because a greater dispersion of returns around the mean causes a larger drop in the compound return.

In addition, trade volume increased as price decreased. This discovered pattern can also mean that investors, based on their sentiments, may overreact because they do not know how to precisely estimate the bitcoin price.

The centralized bitcoin markets demonstrated a higher left tail dependence that is in line with the general pattern in the "traditional" financial markets that are more extreme dependent in downturns. Having long tails, the decentralized bitcoin market does not show a strong pattern of extreme (tail) dependency. Nevertheless, the centralized euro bitcoin markets have a lower average value of tail dependency, and the U.S. dollar exchanges have a superior dependency in terms of extreme low and high returns. The decentralized bitcoin market is more interdependent. Thus, a price setting in the P2P bitcoin markets is not correlated over time or across markets. Correlation between markets is not stable over time and is higher for the centralized exchanges.

Thus, the results support the existing findings regarding bitcoin volatility (Blau, 2018; Katsiampa, 2017; Klein et al., 2018) and extend them with the comparative analysis of the centralized and decentralized bitcoin markets that use the euro, U.S. dollar, and British pound. They also support Pieters and Vivanco's (2017) findings that the bitcoin markets fail to achieve the law of one price (LOOP). Due to the identical nature of all bitcoin, this means that the analyzed bitcoin markets differ in their characteristics. In general, the results are in line 
with the hypothesis that bitcoin performs poorly as a unit of account and as a store of value and can be considered rather as a speculative asset (Corbet et al., 2018; Yermack, 2015).

Overall, these findings are significant and potentially useful to researchers, practitioners, and participants in the highly volatile bitcoin market for making better investment and risk management decisions. Future research can extend the datasets to cover other currencies; focus on higher-frequency bitcoin data, such as hourly (because the results can vary from the current ones); and use other dynamic models based on the concept of copulae, such as the generalized autoregressive score (GAS) framework.

\section{References}

Ang A. and Chen, J. (2002), Asymmetric correlations of equity portfolios. Journal of Financial Economics 63(3) 443-494.

Balcilar, M., Bouri, E., Gupta, R., Roubaud, D. (2017), Can volume predict Bitcoin returns and volatility? A quantiles-based approach. Economic Modelling 64, 74-81.

Baur, D.G., Dimpfl, T., Kuck, K. (2018), Bitcoin, gold and the US dollar - A replication and extension. Finance Research Letters 25, 103-110.

Blau, M.B. (2018), Price dynamics and speculative trading in Bitcoin. Research in International Business and Finance 43, 15-21.

Böhme, R., Christin, N., Edelman, B., Moore, T. (2015), Bitcoin: Economics, Technology, and Governance. Journal of Economic Perspectives 29(2), 213-238.

Bouri, E., Gupta, R., Lau, C.K.M., Roubaud, D. and Wang, S. (2018) Bitcoin and global financial stress: A copula-based approach to dependence and causality in the quantiles. The Quarterly Review of Economics and Finance, https://doi.org/10.1016/j.qref.2018.04.003 
Bouri, E., P. Molnár, G. Azzi, D. Roubaud, and L. I. Hagfors (2017a), On the hedge and safe haven properties of bitcoin: Is it really more than a diversifier? Finance Research Letters 20, 192-198.

Bouri, E., R. Gupta, A. Tiwari, and D. Roubaud (2017b), Does bitcoin hedge global uncertainty? evidence from wavelet-based quantile-in-quantile regressions. Finance Research Letters 000, 1-9. Article in Press.

Chan, W. H., Le, M., Wu, Y.W. (2018), Holding Bitcoin longer: The dynamic hedging abilities of Bitcoin. The Quarterly Review of Economics and Finance, https://doi.org/10.1016/j.qref.2018.07.004.

Charfeddine, L., Maouchi, Y. (2018), Are shocks on the returns and volatility of cryptocurrencies really persistent? Finance Research Letters, https://doi.org/10.1016/j.frl.2018.06.017

Cheah E.T., Fry J. (2015), Speculative bubbles in Bitcoin markets? An empirical investigation into the fundamental value of Bitcoin. Economic Letters 130, 32-36.

Cherubini, U., Luciano, E., and Vecchiato, W. (2004), Copula Methods in Finance. Wiley, Chichester.

Cherubini, U., Mulinacci, S., Romagnoli, S. (2011), A copula-based model of speculative price dynamics in discrete time. Journal of Multivariate Analysis 102, 1047-1063.

Conrad, C., Custovic, A., \& Ghysels, E. (2018). Long- and short-term cryptocurrency volatility components: A GARCH-MIDAS analysis. Journal of Risk and Financial Management 11, 1-12.

Corbet, S., Lucey, B., Peat, M., Vigne, S. (2018), Bitcoin Futures-What use are they? Economics Letters 172, 23-27.

Dyhrberg A.H. (2016), Bitcoin, gold and the dollar - A GARCH volatility analysis Financial Research Letters 16, 85-92. 
Einmahl, J., de Haan, L. and Piterbarg, V. (2001), Multivariate extremes estimation. The Annals of Statistics 29, 1401-1423.

Fermanian, J.-D., Radulovic, D. and Wegkamp, M. (2004), Weak convergence of empirical copula processes. Bernoulli 10, 847-860.

Frahm, G., Junker, M., Schmidt, R. (2005), Estimating the tail-dependence coefficient: Properties and pitfalls. Insurance and Mathematical Economics 37(1), 80-100.

Frees, E. W, Valdez, E. (1998), Understanding Relationships Using Copulae. North American Actuarial Journal 2, 1-25.

Genz, A. (2009), Computation of Multivariate Normal and t Probabilities. Springer. Giacomini, E., Härdle, W. and Spokoiny V. (2009), Inhomogeneous dependence modeling with time-varying copulae. Jourmal of Business and Economic Statistics 27, 224-234.

Gumbel, E. J. (1960), Bivariate Exponential Distributions. Journal of the American Statistical Association 55, 698-707.

Hong, Y., Tu, J., and Zhou, G. (2007), Asymmetries in stock returns: statistical tests and economic evaluation. Review of Financial Studies 20, 1547-1581.

Hu L. (2006). Dependence patterns across financial markets: a mixed copula approach. Applied Financial Economics 16, 717-729.

Ji, Q., Bouri, E., Gupta, R., Roubaud, D. (2018), Network causality structures among Bitcoin and other financial assets: A directed acyclic graph approach. The Quarterly Review of Economics and Finance, https://doi.org/10.1016/j.qref.2018.05.016

Katsiampa, P. (2017), Volatility estimation for Bitcoin: A comparison of GARCH models, Economics Letters 158, 3-6.

Klein, T., Thu, H.P., Walther, T. (2018), Bitcoin is not the New Gold - A comparison of volatility, correlation, and portfolio performance. International Review of Financial Analysis 59, 105-116. 
Lee, L. (1983), Generalized econometric models with selectivity. Econometrica 51, 507-512.

Luther, W. and Salte, A. (2017), Bitcoin and the bailout. The Quarterly Review of Economics and Finance 66, 50-56.

Nelsen, R. B. (2006), An Introduction to Copulas. Second Edition, Springer, U.S.A.

Phillip, A., Chan, J., Peiris, S. (2018), A new look at Cryptocurrencies. Economics Letters 163, 6-9.

Pieters, G. and Vivanco, S. (2017), Financial Regulations and Price Inconsistencies across Bitcoin Markets. Information Economics and Policy 39, 1-14.

Riskmetrics. (1996), Riskmetrics Technical Document, 4th edn. J.P. Morgan: New York.

Schmidt, R. and Stadtmüller, U. (2006), Non-parametric Estimation of Tail Dependence.

Scandinavian Journal of Statistics 33(2), 307-335.

Symitsi, E. and Chalvatzis, K.J. (2018), Return, volatility and shock spillovers of Bitcoin with energy and technology companies. Economics Letters 170, 127-130.

Urquhart, A. (2016), The inefficiency of Bitcoin. Economics Letters 148, 80-82.

Urquhart, A. (2017), Price clustering in Bitcoin. Economics Letters 159, 145-148.

Yermack, D. (2015), Is Bitcoin a real currency? An economic appraisal Handbook of Digital Currency, Elsevier (2015), pp. 31-43.

\section{Appendix}

Appendix 1. Non-parametric estimators of tail dependence (for the detail discussion see Schmidt and Stadtmüller, 2006).

Empirical copula is defined by

$C_{m}(u, v)=F_{m}\left(G_{m}^{-1}(u), H_{m}^{-1}(v)\right),(u, v)^{\prime} \in[0,1]^{2}$

where $C_{m}$ is the empirical copula, $G_{m}$, and $H_{m}$ are the empirical distribution functions corresponding to marginal distribution functions $G, H$. 
Following the definition of tail copulae, (see Equation 1 and Equation 2):

$\Lambda_{L}(x, y):=\lim _{t \rightarrow \infty} \mathrm{tC}(x / t, y / t)$

$\Lambda_{U}(x, y):=\lim _{t \rightarrow \infty} \mathrm{t} \overline{\mathrm{C}}(x / t, y / t)$

the first step of estimators (Genest et al., 1995; Schmidt and Stadtmüller, 2006) known as empirical tail copulae, are

$\widehat{\Lambda}_{L, m}(x, y):=\frac{m}{k} C_{m}\left(\frac{k x}{m}, \frac{k y}{m}\right) \approx \frac{1}{k} \sum_{j=1}^{m} 1_{\left\{R_{m 1}^{(j)} \leq k s \text { and } R_{m 2}^{(j)} \leq k y\right\}}$

and

$\widehat{\Lambda}_{U, m}(x, y):=\frac{m}{k} \bar{C}_{m}\left(\frac{k x}{m}, \frac{k y}{m}\right) \approx \frac{1}{k} \sum_{j=1}^{m} 1_{\left\{R_{m 1}^{(j)} \leq m-k s \text { and } R_{m 2}^{(j)} \leq m-k y\right\}}$

where $R_{m 1}^{(j)}$ and $R_{m 2}^{(j)}$ are the rank of independent and identically distributed (i.i.d.) random vectors $X^{(j)}$ and $Y^{(j)}, j=1, \ldots, m ; k \in\{1, \ldots, m\}, k=k(m) \rightarrow \infty$ and $k / m \rightarrow \infty$ as $m \rightarrow \infty$.

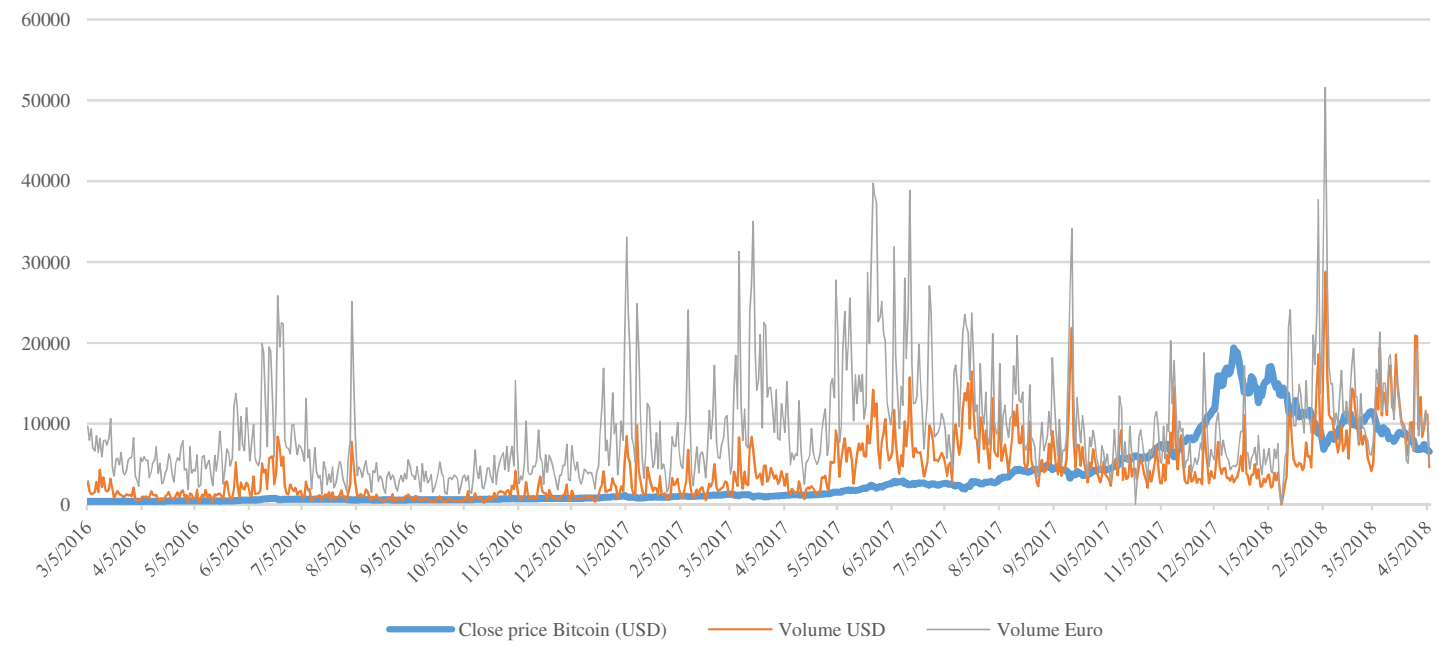

Fig. A1. Trade volumes of bitcoin.

GDAX (euro, U.S. dollar, British pound)
Kraken (euro, U.S. dollar),

GDAX (British pound)
Bitcoin.de (euro), BitStamp

(U.S. dollar), Coinfloor 

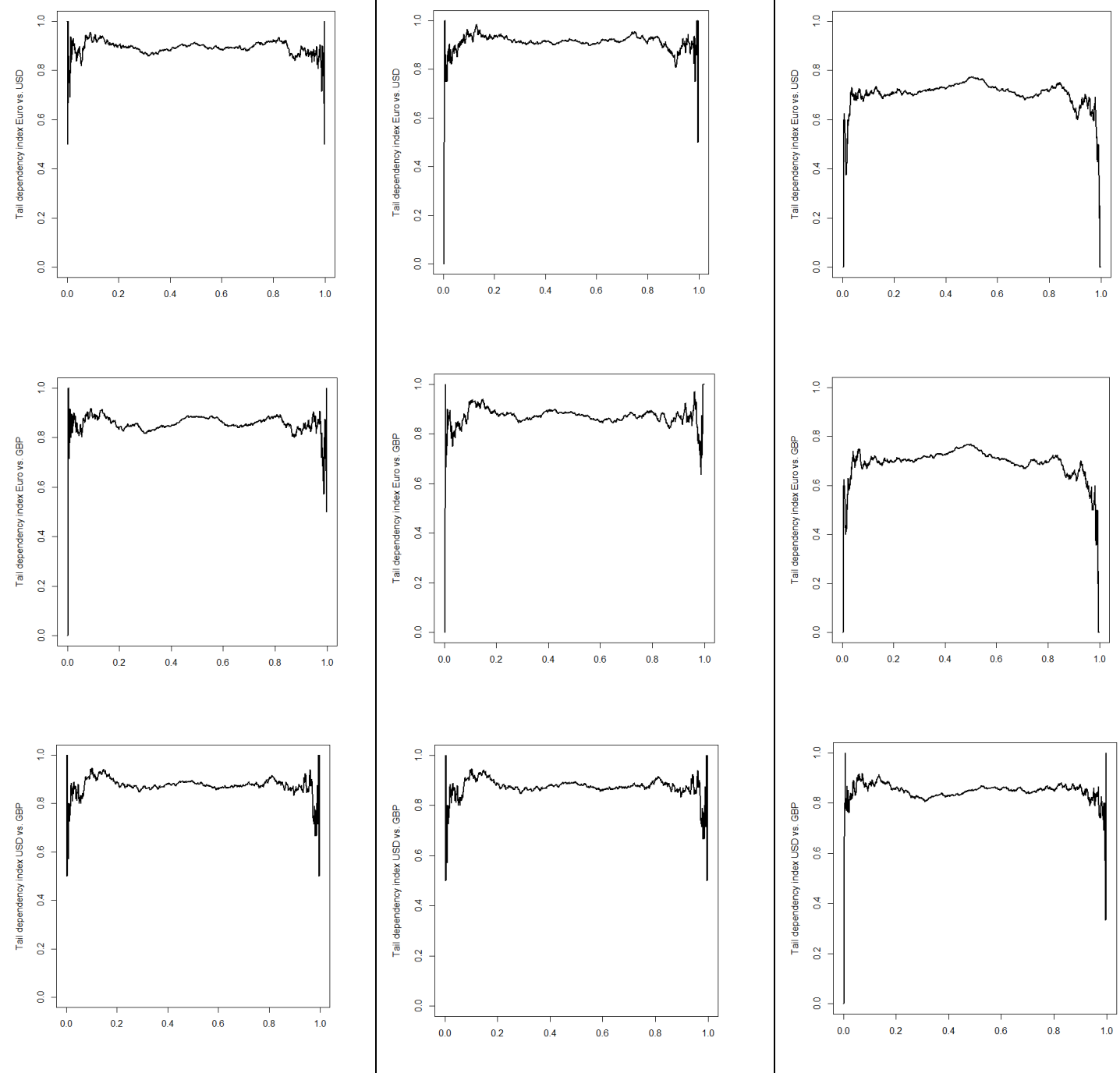

Fig. A2. Tail dependence between the currencies, the centralized bitcoin exchanges, ARMAGARCH copula models.

Note: the ARMA-GARCH models used for residuals calculation are the same as in the EMWA calculations (see Figure 2). 


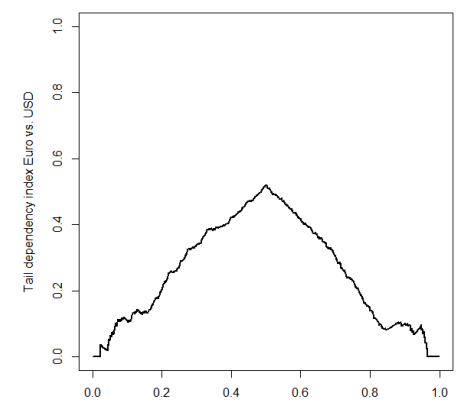

Panel a. Volatility of returns of the euro market

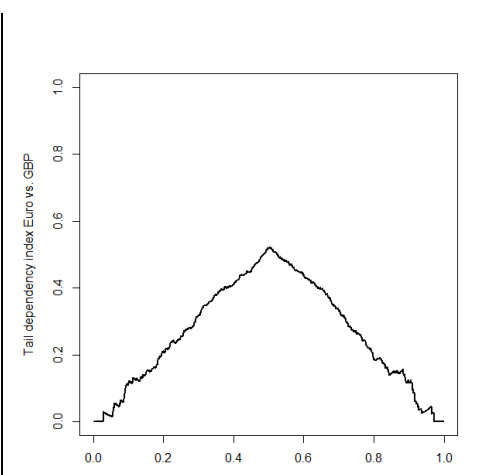

Panel b. Volatility of returns of the U.S. dollar market

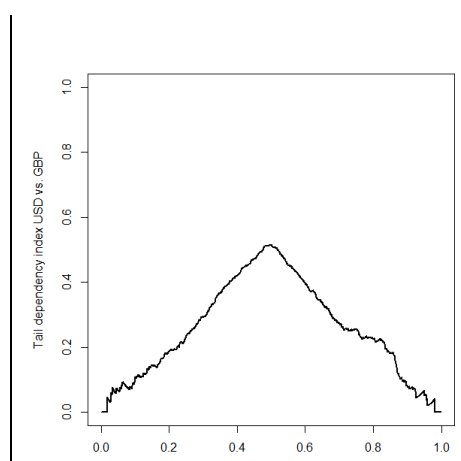

Panel c. Volatility of returns of the British pound market

Fig. A3. Tail dependence between the currencies, the decentralized bitcoin exchange, ARMAGARCH copula models.

Note: the ARMA-GARCH models used for residuals calculation are the same as in the EMWA calculations (see Figure 3). 